\title{
USE OF A GEOSPATIAL EARLY-WARNING DECISION SUPPORT SYSTEM TO PREPARE FOR DISASTERS OR PLAN FOR MULTIPLE HAZARDS: DECATASTROPHIZE
}

\author{
ANDREAS DAMALAS ${ }^{1}$, CHRISTODOULOS METTAS ${ }^{1}$, EVAGORAS EVAGOROU ${ }^{1}$, \\ MARINOS PAPADOPOULOS ${ }^{2}$, ALEXIA KONSTANTINOU ${ }^{2} \&$ DIOFANTOS HADJIMITSIS $^{1}$ \\ ${ }^{1}$ Department of Civil Engineering and Geomatics, Cyprus University of Technology, Cyprus \\ ${ }^{2}$ Ministry of Interior, Cyprus Civil Defence, Cyprus
}

\begin{abstract}
The goal of DECATASTROPHIZE (DECAT) is to use a Geospatial Early-warning Decision Support System (GE-DSS) for rapid deployment, interoperability, transferability and sustainability to assess, prepare for and respond to multiple and/or simultaneous natural and man-made hazards, disasters, and environmental incidents by using existing models/systems in a synergistic way on one multiplatform, distributed and integrated framework called DECAT in five partner countries. The use of GE-DSS combined with integrated Geographic Information System (GIS) solutions fuses text and geographic information into one model and view. In addition to integrating the a) GE-DSS, b) Emergency Operation Centres (EOCs), and c) Operational Resources (OR) in the field in each partner country, the DECAT methodological framework software will also integrate hazard/risk assessment with the common operational picture. No studies using a GE-DSS based framework to integrate and link decision makers, EOCs and ORs in the field for multi-hazard or disaster preparedness in accordance with/relative to the New EU Civil Protection Mechanism preparedness priorities have been carried out or demonstrated. Therefore, this project is expected to a) create better prerequisites for, and improve preparedness, as well as enhance awareness of, civil protection and/or marine pollution professionals and volunteers, b) support and complement the efforts of the participating states for the protection of citizens, environment and property in the event of natural and man-made disasters, c) exchange information, experience, good practice and knowledge aimed at improving the performance of parties involved in civil protection (both private and public professionals and volunteers) and d) support the EU candidate countries and potential candidates not participating in the Mechanism and European Neighbourhood Policy countries in the field of disaster preparedness and enhance their cooperation within the Union Civil Protection Mechanism and its participating states.
\end{abstract}

Keywords: disaster management, disaster preparedness, Geospatial Early Warning Decision Support System (GE-DSS), Humanitarian Aid and Civil Protection (ECHO).

\section{INTRODUCTION}

Developing effective early warning, alert and coordination systems can save lives and protect people, property and the environment in the event of natural and man-made disasters. In its document "Towards Better Protecting Citizens against Disaster Risks: Strengthening Early Warning Systems in Europe" [1], the Commission points out that it seeks to follow a multi-hazard approach, to develop near real time alert systems, to ensure a near real time dissemination of alerts to European Union (EU) Participating States, and to improve its rapid analytical capacity.

Models for single hazards do currently exist. This project focuses on the use and adaptation of existing models, systems or tools in an integrative and synergistic capacity to prepare for disasters and plan for multi hazard incidents. In addition, it addresses/deals with the challenge/gap/issue of integrating risk assessment with the common operational picture. The use of a Geospatial early-warning Decision Support System (GE-DSS), combined with a Geographic Information System (GIS) solution, fuses text and geographic 
Table 1: DECAT consortium.

\begin{tabular}{|c|c|c|c|c|c|c|c|c|c|c|}
\hline \multirow{2}{*}{\begin{tabular}{|c} 
Country \\
\\
\end{tabular}} & \multicolumn{3}{|c|}{ Cyprus } & \multirow{2}{*}{ 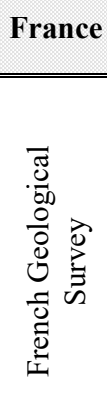 } & \multicolumn{2}{|c|}{ Greece } & \multirow{2}{*}{ 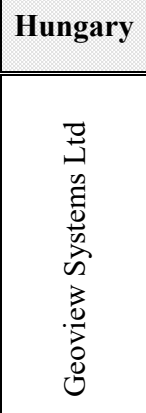 } & \multicolumn{2}{|c|}{ Italy } & \multirow{2}{*}{ 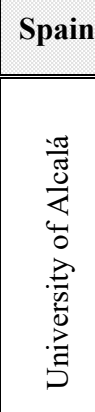 } \\
\hline & 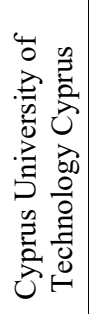 & 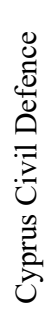 & 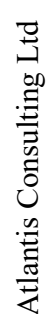 & & 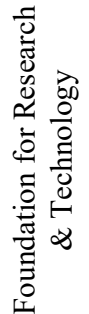 & 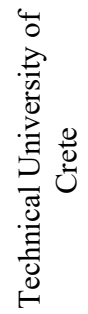 & & 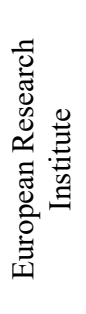 & 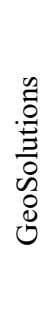 & \\
\hline
\end{tabular}

information into one view. This enables local, regional and national Civil Protection authorities to detect patterns in large collections of documents based on their relationship with locations. Now a standard analysis tool in many intelligence organizations, Civil Protection can leverage geospatial technology with large databases and a DSS to improve situational awareness and preparedness.

The level of preparedness and interoperability within the EU and beyond could be increased by using remote sensing and/or geographic information analysis. The goal of DECATASTROPHIZE (DECAT) is to use GE-DSS for rapid deployment, interoperability, transferability and sustainability to assess, prepare for, and respond to multiple and/or simultaneous natural and man-made hazards, disasters, and environmental incidents by using existing models/systems in a synergistic way on one multi-platform, distributed and integrated framework called DECAT in each partner country.

In addition to integrating the a) GE-DSS, b) Emergency Operation Centres (EOCs), and c) Operational Resources (OR) in the field in each partner country, the DECAT methodological framework will also integrate hazard/risk assessment with the common operational picture. So far, there are very few studies utilizing this geospatial methodological concept and planning to meet specific civil protection priorities. No studies using a GE-DSS based framework to integrate and link decision makers, EOCs and ORs in the field for multi-hazard or disaster preparedness in accordance with/relative to the new EU Civil Protection Mechanism preparedness priorities have been carried out or demonstrated. The countries and organizations (Table 1) that are working on the project, reflect the transnational cooperation on which the multiple disasters, hazards, risks and/or threats focused.

DECAT is currently half-way through its completion so there is no final outcome regarding the project. The methods used in the project and the up to date results are presented below.

\section{METHODS}

In the beginning of the project a questionnaire was distributed to key organizations that work on disaster management, in each partner's country. Also, a hazard and vulnerability analyses, creation of a geo-database and models were performed by each participating nation. 


\subsection{Questionnaire, needs assessment and implementation analysis}

Local and national EOCs in the countries of all beneficiaries were queried (through field visits, semi-structured interviews or questionnaires) as to their potential needs or uses in terms of geospatial decision support systems. The questionnaire or survey was carried out within and in the context of the DECAT project.

\subsection{Hazard and vulnerability analyses}

The objective of this action was to build a hazard profile for each one of the selected hazards that have the potential to occur in each partner country. The hazard profile should include at minimum the following information [2]-[4]: a) the location and boundaries of hazardous areas, b) the magnitude of potential hazards, c) the likelihood of occurrence of hazardous events, d) an analysis of the separate characteristics of potential hazards.

A short hazard and vulnerability report was developed for each of the test areas in the partners' countries to capture the outcomes of this process. It outlined key information on hazards and vulnerability to those hazards. This report was not intended to be exhaustive, but to be used as a reference for future actions in this project [5].

2.3 Data acquisition, creation and design of disaster models and geo-spatial databases for each country's stakeholders

Responsible parties and competent authorities in government agencies were contacted and each partner was responsible for acquiring and collecting the data on their assets, spatial data for hazards and disaster in their own country.

The creation and design of hazard and disaster specific data models for transferability and cross-border civil protection required the creation and integration of a dynamic modelling infrastructure to serve decision makers, end users, managers, policymakers, and researchers. Each partner shared responsibility for collecting and creating data and the database for the high-risk areas identified. It was imperative to create and design data model templates that can be used with one Geospatial Early-warning Decision Support System (GE-DSS) platform, with a view to simplifying the process of implementing projects, making assessments and to promoting and support Member-State standards. The result is that this set of data model structures will be transferable to each of the hazards that can occur in a Member-State, i.e. seismic risk, floods and flooding, earthquake and tsunami, oil spills, wildfires and industrial accidents.

Each partner also shared responsibility for creating the GIS data models for their stakeholders. The data models represent geographic objects or surfaces as data, a set of database design specifications for objects in the GIS applications. The data model described the thematic layers used in the applications, their spatial representation, their attributes, their integrity rules and relationships, their cartographic portrayal and their metadata requirements [6].

\section{RESULTS AND DISCUSSION}

The results of all the actions discussed above can be found in this chapter.

\subsection{Needs Assessment Report and the Common Operational Picture}

The Common Operational Picture (COP) is a single identical display of relevant operational information, such as disaster affected areas, position and status of critical infrastructure and 
critical buildings, position and types of own resources etc., shared by more than one agencies or jurisdictions. Disasters are notorious for extending across multiple jurisdictions, and the modern disaster response operational environment is fraught with a multitude of agencies with different mandates. In addition, multi- agency coordination systems emphasize the need for joint incident action planning in disasters. Therefore, a COP is essential as it facilitates collaborative planning, and assists all involved jurisdictions and responding agencies to achieve situational awareness [7]. The questionnaire mentioned in Methods

Table 2: $\quad$ Summary of the natural hazards receiving the highest marks from responders in each country in order of importance to the country.

\begin{tabular}{|c|c|}
\hline Questions & $\begin{array}{l}\text { 1) Which of the following hazards face your jurisdiction? } \\
\text { 2) For which of the following hazards has your organization conducted hazard studies to } \\
\text { assist disaster management? } \\
\text { 3) For which of the following hazards does your organization use hazard models which can } \\
\text { provide real-time estimations of the hazard-affected area and/or hazard intensity? }\end{array}$ \\
\hline Cyprus & Floods, Wildfires, Earthquake, tsunami, landslide/debris flow, coastal erosion \\
\hline France & $\begin{array}{l}\text { Flood, Hazardous materials transport, Terrorist attack ("SEVESO III" accident), Severe winter } \\
\text { weather, Storm surge, Wildland fire, Earthquake }\end{array}$ \\
\hline Greece & $\begin{array}{l}\text { Coastal erosion, Oil Pollution Marine Incidents, Forest fires, Accidents related to the transport } \\
\text { of hazardous materials }\end{array}$ \\
\hline Hungary & Hazardous materials transport accident, (“SEVESO III" accident), Flood, Severe winter weather \\
\hline Italy & $\begin{array}{l}\text { Earthquakes, landslides and debris flows, floods, wildfires, critical winter conditions, forest } \\
\text { fires, accidents related to the transport of hazardous materials, breaking of the river banks }\end{array}$ \\
\hline Spain & Earthquake, Tsunami, Landslide, Flood, Heat wave, Wildland fire, (SEVESOIII) \\
\hline Question & 4) If yes, are the aforementioned systems stand-alone or network-based? \\
\hline Cyprus & NA \\
\hline France & Network-based tools, Shared GIS tool, Shared studies, standalone tool \\
\hline Greece & Stand-alone and network-based \\
\hline Hungary & Stand-alone and network-based \\
\hline Italy & Stand-alone \\
\hline Spain & Stand-alone and network-based \\
\hline Questions & $\begin{array}{l}\text { W) Which of the following Information Communication Technologies (ICT)-based } \\
\text { capabilities does your organization have? } \\
\text { Which of the following capabilities would you like to be developed and used jointly with } \\
\text { other organizations in your jurisdiction? }\end{array}$ \\
\hline Cyprus & $\begin{array}{l}\text { News media and social network monitoring, Information management and situational report } \\
\text { generation, Task and resource management }\end{array}$ \\
\hline France & $\begin{array}{l}\text { News media \& social network monitoring, Geospatial DB of critical infrastructure and key } \\
\text { resources, RT develop of maps to illustrate the extent of the hazard-affected area and the } \\
\text { intensity of the hazard, Automated response checklists, Information management and situational } \\
\text { report generation, Task and resource management, RT num. simulation of one or more hazards, } \\
\text { RT network based tools (MétéoFrance) }\end{array}$ \\
\hline Greece & $\begin{array}{l}\text { Database of mapping of critical infrastructure and key resources, Information management and } \\
\text { generation of status reports, Management of resources and activities, Numerical simulation in } \\
\text { real time to one or more risks }\end{array}$ \\
\hline Hungary & $\begin{array}{l}\text { Geo-spatial database of critical infrastructure and key resources, News media and social network } \\
\text { monitoring }\end{array}$ \\
\hline Italy & $\begin{array}{l}\text { Numerical simulation in real time to one or more risks. Real-time development of maps to } \\
\text { define the extent of the risk zone and the intensity of the danger. Database mapping of critical } \\
\text { infrastructure and key resources. Management of resources and activities }\end{array}$ \\
\hline Spain & $\begin{array}{l}\text { Real-time development of maps to illustrate the extent of the hazard-affected area and the } \\
\text { intensity of hazard, News media and social network monitoring, Geospatial database of critical } \\
\text { infrastructure and key resources, Information management and situational report generation, } \\
\text { Task and resource management, Geospatial database of critical infrastructure and key resources, } \\
\text { Automated response checklists }\end{array}$ \\
\hline
\end{tabular}


(Section 2) was performed to assess the needs of EOCs in terms of geospatial decision support systems to support interoperability in disaster response operations. This survey was carried out within, or in the context of, the DECAT project. Table 2 shows the summary of the natural hazards receiving the highest marks from responders in each country in order of importance to the country.

\subsection{Hazard and Vulnerability Reports (H\&VA)}

In DECAT, disaster risks are considered as the combination of one or more hazards with vulnerabilities to these hazards. The following sections are intended as guidelines for the conduct of DECAT's hazard and vulnerability analyses. These H\&VAs are not expected to be fully-developed disaster risk assessments, rather they are intended as a design tool. In addition, a lot of information may not be readily available to project partners for any number of reasons. Therefore, it is expected that DECAT's H\&VA will be less detailed compared to a "real" disaster risk assessment, hazard mitigation or disaster prevention plan. In other words, the level of detail included in the H\&VAs is at the discretion of every project partner. A table indicating the results of these reports was created (Table 3). It shows a summary of the H\&VA reports of each participant country.

\subsection{Acquisition, collection and integration of datasets and resources in the DECAT framework database}

This database will represent Civil Protection (CP) assets, data, shapefiles, resources and CP response capacities and that can be deployed to international emergency interventions. Partners aimed to maintain good communication channels with the competent authorities. To reciprocate, each partner shares and presents the application of the SDSS for their purposes. Multiple feature classes of these assets and shapefiles were created based upon minimum and common categories for layers relative to the disasters, hazards, and risks in each country. Table 4 is presenting the data collected and analysed by each participating country.

\subsection{Data models}

Models or systems for single occurrences of disasters or hazards which currently exist to prepare for single occurrences whether it is for a disaster, hazard, incidents, or industrial accidents. The models used were for floods and flooding, seismic risk, earthquake and tsunami, oil spills, wildfires and industrial accidents. A review of the models which currently exist to prepare for single occurrences and the results of this project shows that mostly all the countries need to assess, design for and mitigate multiple occurrences of disasters or hazards which are currently in their country. Anticipated or expected models or systems for multiple occurrences of disasters or hazards that were used in the DECAT framework for each country are described in Table 5. Vulnerabilities to hazards in areas where there is rapid population growth and economic development in hazard-prone areas have greatly increased the potential of multiple hazards to cause environmental damage and destruction to natural resources, residences, buildings, bridges, and infrastructure. Although an individual hazard is significant in many parts of the world, in certain areas more than one hazard may pose a threat to built-up and rural environment. So, to address multiple hazards in an integrated manner, it is important to integrate the anticipated or expected models or systems in each country. The growing interest and importance of multiple-hazard engineering has been recognized recently in Europe and the USA. This stimulated the evolution of multiple-hazard risk-assessment frameworks such as the which will be designed in DECATASTROPHIZE. 
Table 3: Information and/or variables requested to produce the hazard profile.
Delineation of the location and boundaries of hazardous areas.
1. Delineation the magnitude of potential hazards
2. Delineation of the likelihood of occurrence of hazardous events
3. Description and analysis of the separate characteristics of potential hazards.

Floods and flooding: risk maps were created for 19 areas of streams showing the following:

1) Possibility of flooding and Sensitive infrastructure 2) Consequences of three scenarios of

$\simeq$ flooding predicting the potential adverse consequences of flooding of low, medium and high

probability illustrating the maximum number of residents potentially affected by the rapid growth of urban areas in each zone, the land uses and the type of economic activity based on zoning in areas likely to be affected, sensitive infrastructure, protected Areas, and installations [8].Wildfires: application of static forest fire risk assessment map to predict impact on local economies and the potential for loss of life was determined for all municipalities [9].

Seismic risk: mainland-France has a low to medium seismicity characterized by "diffuse" seismicity concentrated largely in mountainous areas. The qualification of the seismic hazard delineates France into five seismic zones. Flood Hazard: French PFRAs has defined the

\& delineation of hazardous area through two "approached envelopes of potential floods"

플 corresponding to extreme phenomena [10]; 122 areas of APSFRs is identified in France.

I Landslides: $20 \%$ of the French municipalities are affected and delineated and particularly strong in mountainous areas, alongside the coastal cliffs, valleys where the underlying rocks was strongly eroded by the rivers. Delineation of hazardous areas and vulnerability to landslides comes from the "Classified European Landslide Susceptibility map v1.0" [11].

$\approx$ Marine oil spills: delineation of the location and boundaries of hazardous areas: high intensity shipping routes, definition of areas to be licensed for exploration and exploitation of hydrocarbon, the magnitude of potential oil spills determined within a range, by assessing the likelihood of occurrence of hazardous event: marine oil spills are highly likely to continue to present a risk in Greece. According to historical data on average two accidents with pollution incidents occur per year.

Floods and flooding: the Danube River runs and bends through Hungary and floods periodically. Analysing and understanding the background levels delineates high/highest water levels and the

. $\Xi$ situations show a special cyclicality [12]. Wildfires: Forest fire occur and can be mitigated or eliminated by the collaborative intervention of the disaster management and other organizations, but the lack of this increases hazards and fires spread quickly. Environmental and weather conditions contributed to the rapid spread of the fire.

Seismic hazard and vulnerability is delineated, mapped, and monitored using "Shake Maps", tables and basic maps. Flood hazard maps and tables from ISPRA reports (2015) are the essential source for information and variables to produce hazard profiles, and Vulnerability Assessments. Additional summaries: Region of Sardinia: $31 \%-45 \%$ of the region is

$\geq \quad$ affected mainly by wildfires, hydrogeological instability, and coastal erosion hazards.

I Province of Alessandria: $36.96 \%$ of the territory is affected by landslides and $42 \%$ of the Province, the most exposed is Piedmont, with $38 \%$ of disasters, occurring mainly during the winter thaw, and during the rainy season. $40 \%$ of the landslides are due to collapses, $30 \%$ are due to in water flows and $20 \%$ are of different kinds. Areas having landslide and flood risk in 190 municipalities are delineated by percentages and classified based on the degree of severity [13]-[15].

Forest fires: geographical delineation and distribution of forest fires show all information, factors, and variables requested to produce hazard profiles with certain homogeneity in mainly these provinces or regions: Northwest, Mediterranean Coast, Canary Islands, and interior regions

$\Xi \quad$ (except León and Zamora) depending on the weather, fuel and topographical models.

के Floods: analysis and assessment methodology for Flooding Potential Significant Flood Risk Areas (ARPSIs) and all associated parameters are delineated and carried out for multiple scenarios [16]. Earthquakes: Spain does not represent a large earthquake hazard area or occurrence. Volcanoes: the only interesting region to develop volcanic risk studies is the Canary Islands. Hazard maps are drawn through lava flows, ash fall and pyroclastic flows analysis. 
Table 3: Continued.

Assessments conducted or performed to assess vulnerability

1. Assessment of the number of people exposed to hazards, including special populations.

2. Assessment of the value of assets or property exposed to hazards

3. Assessment of the number of critical facilities exposed to hazardous forces

4. Assessment of the danger from secondary hazards (e.g. dam breaking).

5. Assessment of the danger from hazardous facilities (e.g. nuclear or chemical plant) in hazard areas.

6. Assessment of the danger from exposure to hazardous materials in wake of natural disaster.

7. Assessment of environmental impacts of the disaster.

Floods \& flooding: assessments were/are based on geo-referenced.

1) No. of residents potentially affected by the rapid growth of urban areas in each zone.

2) Estimate of the population potentially affected made by combining satellite image showing the growth rate of the planning zones, and the listed population of full development zone.

3 ) Land uses and the type and degree of economic activity based on zoning in areas likely to be

affected distinguished on the maps with different colour gradients 4) Sensitive infrastructure

5) Protected Areas (archaeological sites and areas Natura network 2000).

Wild fires: 1) Areas exposed to damages when threatened by forest fires as indicated by the Forestry Department Risk Assessment maps 2) National plan updated yearly with all municipalities/communities and populated areas in the countryside listed 3) The land uses and the type of economic activity based on zoning in areas likely to be affected. 4) Sensitive Infrastructure 5) Protection Areas (archaeological sites and areas Natura network 2000). 6) Critical facilities and installations that may cause accidental pollution in case of fire.

Seismic risk: indicators based on French seismic zonation, and the location of the resident

population classified SEVESO industrial facilities. Flood hazard: indicators about exposure of

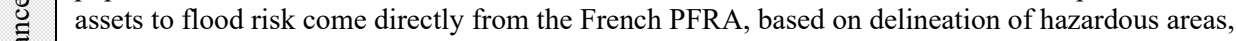

运 and the location of the resident population, hospitals, built areas, etc. Landslides: Indicators about exposure of assets to landslides have been derived based on susceptibility map, and in the second hand the location of the resident population or classified.

Marine oil spills: Shoreline vulnerability maps of Crete and maps created assess: 1) The shoreline type, 2). The biological resources located on the shoreline:

- The human-use resources \& infrastructures located on the shoreline of critical facilities: 1) Coastal cultural and archaeological sites, 2) popular beach sites, 3) Marinas and ports,

$\because \quad 4$ ) large cities, 5) Industrial sites. Assessment of the danger of potential losses from oil spills include human life (fires and explosions near oil spills and rigs, breathing of gaseous oil compounds, skin adsorption, and natural resources.)

- Oil spills penetrate and affect plumage of birds and the fur of mammals making them more vulnerable to temperature fluctuations and much less buoyant in the water and represent an immediate fire and explosion hazard, especially when associated with offshore oil and gas exploration and mining activities.

Floods and flooding: vulnerability assessments were/are based on: 1) Water management and factors or variables on the water from catchment areas -hydrological, meteorological, geographical and nature protection point of view, hazard control and mitigation plans,

2) Plans and processes for building dams accounting for water capacity and proximity

to infrastructure and populations, 3) Environmental impacts to:

- Facilities with dangerous materials;

- Habitats protected for nature conservation.

Wildfires: assessments are based on: 1) proximity to inhabitants, settlements, roads, farms affected 2) protected property 3 ) critical infrastructure.

Industrial Accidents: assessments are based on: 1) elements and means of transport,

2) quality of surface and groundwater, 3) ICT network, 4) healthcare, 5) industrial sector,

6) dependence on weather conditions for transport, fate, and effects of hazardous gases,

7) environmental impacts/effects on wildlife and humans. 
Table 3: Continued.

Assessments conducted or performed to assess vulnerability

8. Assessment of the number of people exposed to hazards, including special populations.

9. Assessment of the value of assets or property exposed to hazards

10. Assessment of the number of critical facilities exposed to hazardous forces

11. Assessment of the danger from secondary hazards (e.g. dam breaking).

12. Assessment of the danger from hazardous facilities (e.g. nuclear or chemical plant) in hazard areas.

13. Assessment of the danger from exposure to hazardous materials in wake of natural disaster.

14. Assessment of environmental impacts of the disaster.

\begin{tabular}{|c|c|}
\hline & $\begin{array}{l}\text { Municipality of Vittoria: daily, the Operational Centre of the National Civil Protection } \\
\text { Department writes a bulletin about the possibility and vulnerability of earthquake risk, } \\
\text { forest fire risk, hydrogeological and flood risk, and it publishes it on a dedicated website, } \\
\text { with restricted access. Assessments are based on the above data and ISPRA reports (2015) on the } \\
\text { following: geomorphological and flood risk/hazard and vulnerability, municipal areas which are } \\
\text { potentially subject to flooding and landslides. Landslide hazard areas, divided and classified by } \\
\text { their seriousness level. }\end{array}$ \\
\hline & $\begin{array}{l}\text { Forest fires: vulnerability assessments were/are based on geo-referenced and spatial factors which } \\
\text { include: exposure of population, properties, systems or resources threatened by forest fires } \\
\text { and therefore exposed to potential losses. Vulnerability estimation uses elements exposed to a } \\
\text { particular level of forest fires risk characterized by: Population Index, Infrastructures Index, } \\
\text { Environmental Uniqueness Index. Then, vulnerability is assessed and classified by potential risk } \\
\text { calculation for each municipality obtained from matrix calculation values crossing } \\
\text { Hazard Local Index and Vulnerability Index for each municipality for all national territory. } \\
\text { Earthquakes: Existing vulnerability studies are carried out by the regions within emergency plans, } \\
\text { specified for each region. Buildings vulnerability depends on multiple factors: } \\
\text { constructive and structural typology, geometry, height, conservation level, age and use. }\end{array}$ \\
\hline
\end{tabular}

Table 4: Data products acquired, collected and integrated in the DECAT SDI for the GE-DSS and DECAT Framework for Disasters, Hazards, and Risks in each country.

\begin{tabular}{|l|c|c|c|c|c|c|}
\hline \multicolumn{1}{|c|}{ Hazard } & Cyprus & France & Greece & Hungary & Italy & Spain \\
\hline Coastal erosion & & & & & $\mathrm{x}$ & \\
\hline Earthquakes / tsunami & $\mathrm{x}$ & $\mathrm{x}$ & $\mathrm{x}$ & & $\mathrm{x}$ & $\mathrm{x}$ \\
\hline Floods and flooding & $\mathrm{x}$ & $\mathrm{x}$ & & $\mathrm{x}$ & $\mathrm{x}$ & $\mathrm{x}$ \\
\hline Marine oil spills & $\mathrm{x}$ & & $\mathrm{x}$ & & & \\
\hline Wild fires & $\mathrm{x}$ & & $\mathrm{x}$ & $\mathrm{x}$ & $\mathrm{x}$ & $\mathrm{x}$ \\
\hline Land slides & & $\mathrm{x}$ & & & $\mathrm{x}$ & \\
\hline Industrial accidents & & & & $\mathrm{x}$ & & \\
\hline
\end{tabular}


Table 5: Anticipated or expected models or systems for multiple occurrences of disasters or hazards that will be used in the DECATASTROPHIZE framework for each country. (References are provided for name, site, source and/or URL given for description of model, system or occurrences.)

\begin{tabular}{|c|c|}
\hline \multicolumn{2}{|c|}{ Seismic risk, earthquakes/tsunami } \\
\hline France & “PAGER" - SEISAid model. \\
\hline Greece & Method of Splitting Tsunami (MOST). \\
\hline Italy & $\begin{array}{l}\text { Vittoria: The Monitoring model is based on the Civil Protection municipal plan. } \\
\text { Sardinia: No planned program. } \\
\text { Alessandria: Department Projections Systems of Arpa Piemonte and they are part of } \\
\text { the regional seismic network of Northwestern Italy nordoccidentale [17]. }\end{array}$ \\
\hline \multicolumn{2}{|c|}{ Floods and flooding } \\
\hline Cyprus & HEC-GEOHMS and HEC-GEORAS [18], [19]. \\
\hline Hungary & Mesoscale Hydrologic Model (mHM) [20], [21]. \\
\hline Italy & $\begin{array}{l}\text { Vittoria: The Monitoring Model is based on the Civil Protection municipal plan. } \\
\text { Alessandria: Piedmont Region adopts an alert system, according to the Directive of the } \\
\text { President of the Council of Ministers of } 27 \text { February } 2005 \text { [22]. } \\
\text { Sardinia: 1) Mike } 11 \text { (hydrodynamic modelling of the risk for the Flumendosa Basin, } \\
\text { while it is still under preparation for some other river basins of the Region [23]); } \\
\text { 2) Bundle rain index risk - hydrogeological (ARPAS); } \\
\text { 3). Efforts Software - under implementation - (developed by Progea [24]). }\end{array}$ \\
\hline \multicolumn{2}{|c|}{ Marine Oil spills } \\
\hline Greece & MEDSLIK-II [25]. \\
\hline \multicolumn{2}{|c|}{ Wildfires (including forest fires) } \\
\hline Cyprus & STATIC FIRE INDEX model [9]. \\
\hline Greece & FARSITE [26]. \\
\hline Hungary & Fire hazard, fire risk, fire severity, fire danger, fire breaks. \\
\hline Italy & $\begin{array}{l}\text { Vittoria: The Monitoring model is based on the Civil Protection municipal plan. } \\
\text { Sardinia: 1) IFI Ichnusa Fire Index model [27]; 2) Forest expedite model (developed at } \\
\text { the Forest and Environmental Monitoring Service of Sardinia Region); } \\
\text { 3) Fires Weather Index (developed by ARPAS Sardinia [28]); 4) Prefer [29]; 5) Risico } \\
\text { (Fire Risk and Coordination - CIMA Foundation). } \\
\text { Alessandria: 1) Convention between Piedmont Region-Forest fire-fighting department, } \\
\text { the National Forestry Authority and Arpa Piemonte [30], in partnership with IPLA. } \\
\text { S.p.A- a daily information service for the forest fire risk prediction on the territory, } \\
\text { 2) Fire Weather Index (FWI) developed by the Forest Fire Prevention Service of } \\
\text { Canada [31]. 3) Alpine Forest Fire warning System, (ALP FFRIS [32]) that is an } \\
\text { alpine forest fire alert system. }\end{array}$ \\
\hline Spain & Wildfire Analyst forest fire model. \\
\hline \multicolumn{2}{|c|}{ Land Slides } \\
\hline Spain & $\begin{array}{l}\text { Alessandria: 1) Arpa Piemonte manages the Regional Network of Control } \\
\text { on Landslide movements called ReRCoMF and widespread within the whole regional } \\
\text { territory, with } 300 \text { monitoring sites [30], 2) Regional Functional Centre has developed } \\
\text { a model, called TRAPS (Translational / Rotational slides Activation Prediction } \\
\text { System) [33]. }\end{array}$ \\
\hline
\end{tabular}


3.5 Natural disaster and hazard models linked to infrastructure and stakeholders

The purpose of this activity (Table 6) was to encourage and urge stakeholders involved in disaster management to think "outside the box" and move from strictly responding to disasters to mitigating, preparing, and/or preventing them. The combination and interaction of elements (synergy or linkage between and among) of data models used, features/layers related to assets, and hazards (elements at risk, end users at risk, frequency and severity of risk, infrastructure geo-spatial scale, length or span of threat, affected resources) present some unique difficulties in preparing adequately for multiple disasters, hazards or threats or dealing with their effects. Each partner or participant collaborated and worked closely with stakeholders, end-users and competent authorities, including the traditional disaster responders - police, firefighters, and civil protection personnel. The stakeholder and end-user list was extensive, including industry, labour, academia, government agencies, non-governmental organizations, and professional organizations both domestic and international. Other users of CUT technology and scientific findings could include peer reviewers, recipients of research grants and contracts, or sources of equipment, technology, or academicians applying the knowledge to advance research in the disaster preparedness and response community. Disasters and Hazards with database and data models were linked to infrastructure and relevant stakeholders in each country. The results, entitled by the name of the database for each country, organized the knowledge and information for each disaster using the following format:

\section{CONCLUSIONS}

It is evident that countries can have many hazards. Most are natural and others are manmade. In the past, design, mitigation and preparedness strategies were often limited to mitigating or prepare for the effects of individual hazards. However, such strategies may prepare communities, municipalities or regions to specific hazards, but in some cases these measures may make them more vulnerable to other hazards. Without regard to or consideration of the origin of the hazard or disaster, having each partner complete a questionnaire and conduct a hazard and vulnerability risk assessment in each country helped to identify and rank disasters and hazards to better prepare for them.

Preparedness is the aspect, step, and strategy in the Disaster Management Cycle that makes it possible for households, organizations, and other units of analysis to manage both preparatory activity and response processes. Preparedness is planning how to respond, and examples include preparedness plans, emergency table-top exercises (TTX) and training, warning systems identifying lines of authority and responsibility, and specifying how resources will be managed, information analysed and decisions made.

Table 6: Geodatabase structure example.

\begin{tabular}{|c|c|c|c|c|c|c|}
\hline \multicolumn{7}{|c|}{ Database name: DECAT_geodatabase_CY.gdb } \\
\hline \multirow{3}{*}{$\begin{array}{c}\text { Disaster/ } \\
\text { Hazard }\end{array}$} & \multirow{3}{*}{$\begin{array}{c}\text { Data } \\
\text { Model } \\
\text { used }\end{array}$} & \multicolumn{4}{|c|}{ Features/layers } & \multirow{3}{*}{ Stakeholders } \\
\hline & & \multirow{2}{*}{$\begin{array}{l}\text { Hazard } \\
\text { related }\end{array}$} & \multicolumn{3}{|c|}{ Assets related } & \\
\hline & & & $\begin{array}{c}\text { Elements } \\
\text { at risk }\end{array}$ & Infrastructure & $\begin{array}{c}\text { End users } \\
\text { at risk }\end{array}$ & \\
\hline
\end{tabular}


In summary, the consortium found 1) consistencies among core areas, locations, proximity to, and types of disasters, risk, hazard and vulnerability among countries, and how to address preparedness in these areas, 2) the need among countries to prepare for and/or plan for multiple hazards, including where, when, how, and for what hazard(s), 3) how to make better decisions based on past hazard experiences, 4) what responses to questions think are important, and 5) the elements at risk from stakeholders. To this end, one of the objectives of this project is to develop a framework and associated software which can integrate data using a SDSS to make decisions in case of multiple hazards that will be tested in different countries and for different multiple hazards which could occur in that country.

\section{REFERENCES}

[1] European Commission, Towards better protecting citizens against disaster risks: strengthening early warning systems in europe EN, 2007.

[2] Godschalk, D.R. et al., Making mitigation work: recasting natural hazards planning and implementation, 1997.

[3] Brower, D.J. \& Bohl, C.C., Principles and practice of hazard mitigation, 2000.

[4] Schwab, D.J., Eschelbach A.K. \& Brower, K., Hazard Mitigation and Preparedness, John Wiley \& Sons: Hoboken, NJ, 2007.

[5] CUT and CCD, Deliverable 3.3: Cyprus hazard and vulnerability DECATASTROPHIZE project, 2016.

[6] CUT, Deliverable 4.3: Cyprus hazard and vulnerability report: geospatial databases of natural disasters and hazard models linked to infrastructure and stakeholders of each country - DECATASTROPHIZE project, 2017.

[7] Karagiannis, J.M., Piatyszek, G.M. \& Flaus, E., Industrial emergency planning modeling: A first step toward a robustness analysis tool. J. Hazard. Mater, pp. 324334, 2010.

[8] WDD, Water Development Department-WDD, 2016 Online. http://www.moa.gov. cy/moa/wdd/Wdd.nsf/All/DDE8D54ED59CE787C2256C7C0036BD20?OpenDocu ment\&highlight $=$ risk maps.

[9] DOF, Department of Forests (DOF), 2016, Online. http://www.moa.gov.cy/moa/fd/ fd.nsf/AdvancedSearch_en?OpenForm $\& \mathrm{q}=\& \mathrm{p}=1 \& \mathrm{w}=\& \mathrm{t}=\& \mathrm{~s}=$ fires $\& \mathrm{~L}=\mathrm{E} \& \mathrm{e}=\& \mathrm{i}=1$.

[10] European Union, directive 2007/60/ec of the european parliament and of the council of 23 October 2007 on the assessment and management of flood risks. Off J. Eur. Union, pp. 27-34, 2007.

[11] Günther, A. et al., Tier-based approaches for landslide susceptibility assessment in Europe-Classified European Landslide Susceptibility map v1.0. Landslides, 10(5), pp. 529-546, 2013.

[12] ICPDR, 2010 Floods in the Danube River Basin, 2010.

[13] ISPRA, Hydrogeological instability in Italy hazard and risk indicators, 2015.

[14] ISRA, Landslides and floods in Italy ISPRA maps and the new plaform web of \#italiasicura, 2015.

[15] Trigila, A., Iadanza, C., Bussettini, M. \& Lastoria, B., Hydrogeological instability in Italy hazard and risk indicators - Dissesto idrogeologico in Italia: pericolosità $\mathrm{e}$ indicatori di rischio, 2015.

[16] ISO/TC, Risk management, Risk assessment techniques, 2009. IEC 31010:2009.

[17] RSNI, Regional Seismic network of Northwestern Italy, 2017, Online. http://www.distav.unige.it/rsni/.

[18] US Army Corps of Engineers, HEC-GEOHMS, Online. http://www.hec.usace.army. $\mathrm{mil} / \mathrm{software} /$ hec-geohms/. 
[19] US Army Corps of Engineers, HEC-GEORAS, Online. http://www.hec.usace.army. $\mathrm{mil} / \mathrm{software} / \mathrm{hec}-\mathrm{georas} /$.

[20] Samaniego, L., Kumar, R. \& Attinger, S., Multiscale parameter regionalization of a grid-based hydrologic model at the mesoscale, Water Resour. Res., 2010.

[21] Samaniego, L., Kumar, R., \& Attinger, S., Implications of distributed hydrologic model parameterization on water fluxes at multiple scales and locations. Water Resour. Res., 2013.

[22] European Union, Directive of the President of the Council of Ministers of 27 February 2005, 2005.

[23] MIKE11, Hydrodynamic modeling of the risk for the Flumendosa Basin, Online. http://www.mikepoweredbydhi.com/products/mike-11.

[24] Progea, EFFORT support system, 2017, Online. http://progea.net/prodotti.php? $\mathrm{p}=$ EFFORTS\& $\mathrm{c}=$ Software \&lin $=$ inglese.

[25] MEDSLIK-II, Oil spill model, 2012, Online. http://medslikii.bo.ingv.it/.

[26] USDA-FARSITE, Fire, Fuel, and Smoke Science Program, Online. https://www.firelab.org/project/farsite.

[27] Uniss-Dipnet, Proterina2, software di previsione e monitoraggio pericolosità da incendi boschivi, 2014.

[28] Sardegna Arpa, ARPAS Sardinia, 2017.

[29] EU FP7, PREFER project, 2012.

[30] ReRCoMF, Regional Network of Control on Landslide movements, 2002.

[31] Wagner, V., Fire Weather Index (FWI), Forest Fire prevention Service of Canada, 1984.

[32] ALP FFIRS, Alpine Forest Fire warning system, 2009, Online. http://www.alpffirs.eu/.

[33] Tiranti, D., Rabuffetti, D., Salandin A. \& Tararbra, M., Development of a new translational and rotational slides prediction model in Langhe hills (north-western Italy) and its application to the 2011 March landslide event. Landslides, 10(2), pp. 121-138, 2012.

\section{ACKNOWLEDGEMENT}

This project has received funding from the European Union's Directorate-General humanitarian aid and civil protection - ECHO under Grant Agreement ECHO/SUB/2015/713788/PREP02. 